\title{
In silico Modelling of 2D, 3D Molecular Descriptors for Prediction of Anticancer Activities of Luteolin And Daidzin From Plants Perilla ocymoides L and Glucine max $L$
} \author{
Ngoc $\mathrm{Han}^{3}$ \\ ${ }^{1}$ Faculty of Chemistry, Hue University of Science, Asia \\ ${ }^{2}$ Faculty of Chemistry, Hue University of Education, Asia \\ ${ }^{3}$ Faculty of Science and Engineering, Hoa Sen University, Asia \\ ${ }^{4}$ Institute of Chemical Technology, Vietnam Academy of Science and Technology, Asia
}

Pham Van Tat ${ }^{3 *}$, Bui Thi Phuong Thuy ${ }^{1}$, Tran Duong², Phung Van Trung ${ }^{4}$, Hoang Thi Kim Dung and Pham Nu

Submission: October 10, 2017; Published: November 20, 2017

*Corresponding author: Pham Van Tat, Faculty of Science and Engineering, Hoa Sen University, Asia, Email: vantat@gmail.com

\begin{abstract}
Recently, we have isolated two flavonoids luteolin and daidzin from leaves of Perilla ocymoides $L$ and Glucine max $L$ in Viet Nam [1], with cytotoxic activity relatively strong in Hela cell line. To clarify the important nature of the relationships between structure and activity, the QSAR studies on Hela cell line incorporated the principal component analysis (PCA) technique and the artificial neural network (ANN) to construct the $\mathrm{QSAR}_{\mathrm{PCAANN}}$ relationships. The best multiple linear model $\mathrm{QSAR}_{\mathrm{MLR}}$ (with $\mathrm{k}=6$ ) values $\mathrm{R}_{\text {train }}^{2}$ of 0.854 and $\mathrm{R}_{\text {pred }}^{2}$ of 0.812 , and QSARPCR (with $\mathrm{k}=6$ ) values $\mathrm{R}_{\text {train }}^{2}$ of 0.937 and $\mathrm{R}^{2}$ pred of 0.889 were found by using the multiple linear regression technique. The artificial neural network $\mathrm{QSAR}_{\mathrm{PCA}-\mathrm{ANN}}$ with architectural style I (6)-HL (9)-O (1) represented the values $\mathrm{R}_{\text {train }}^{2}$ of 0.993 and $\mathrm{R}_{\text {pred }}^{2}$ of 0.971 . In the case the incorporated model QSAR $\mathrm{PCA}_{\text {- }}$ ${ }_{\text {NNN }}$ with the architecture I (6)-HL (9)-O (1) was exhibited the higher training and predicted quality. The anticancer activities of test substances resulting from those models are in good agreement with those from literature. The anti-cancer activities of two compounds luteolin and daidzin from leaves of Perilla ocymoides $L$ and Glucine max $L$ resulting from those models turn out to be agreement with experimental data.

Keywords: $\mathrm{QSAR}_{\mathrm{MLR}} \mathrm{QSAR}_{\mathrm{PCR}}$ and $\mathrm{QSAR}_{\mathrm{PCA}-\mathrm{ANN}}$ Model; Anti Cancer Activities Hela Cell Line

Abbreviations: PCA - Principal Component Analysis; ANN - Artificial Neural Network; QSAR - Quantitative Structure-Activity Relationship; PCR - Principal Component Regression; PCs - Principal Components; SE - Standard Error; LOO - Leave-One-Out; HMBC - Heteronuclear MultipleBond Correlation; HSQC - Heteronuclear Single-Quantum Correlation spectroscopy; QSAR - Quantitative Structure Activity Relationship; MLR - Multiple Linear Regression
\end{abstract}

\section{Introduction}

Natural products from plants are of interest in searching for new anti-cancer drugs and can have a direct effect on HeLa cell line and reduce side effects. Recently, we have isolated a few flavonoids from Perilla ocymoides $L$ and Glucine max $L$ [1] and tested in vitro activities pointed out the relatively strong impacts for cancer cells HeLa [2]. Flavonoids are polyphenolic compounds in most plants [3-5]. The flavonoids from Perilla ocymoides $L$ and Glucine max $L$ were also tested the biological activities in some different cancer cells. The flavonoids presented their activities and role of food within flavonoids in the cancer inhibition are widely studied [6-8]. In recent years, the computational methods are applied widely for the study of chemical properties and designing new drugs. The field of new drug design by in sillico method has become an important tool nowadays. In sillico study on quantitative relationships between structure and activity (QSAR) of natural products is concerned with the new drug researchers and pharmaceutical manufacturing facilitators. In Viet Nam, there are also a number of works of scientists from universities and institutions published in Viet Nam journals [9-11]. In the previous studies of 3-aminoflavonoid substances they have focused on the use of semi-empirical calculation [11]. Those studies showed an effect way for designing new drugs with the assisted computers. The In sillicao model it can be used to predict the biological activity of new drugs from the atomic 


\section{Organic and Medicinal Chemistry International Journal}

charges and molecular descriptors. This method allows for the identification of an active-central location of molecule.

The set of flavones and isoflavones is known to have an important activity against cervical cancer cells [12-14]. This flavonoid group is also interested currently for researching in different directions such as the synthesis and metabolizing of natural products isolating them from plant [1]. The in sillico model of quantitative relationship between the structure of flavones and isoflavones and anticancer activity is an important issue for searching the flavonoid derivatives to be valid way. In this work, we report in the present paper the use of semi-empirical quantum calculations and construction of quantitative structure activity relationship (QSAR) models using 32 flavone and isoflavone derivatives [15]. The geometries of flavones and isoflavones are optimized by means of molecular mechanics $(\mathrm{MM}+)$. The 2D and 3D molecular descriptors resulting from geometric calculation are used to establish the multivariate models such as multiple linear regression (MLR), principal component regression (PCR) and artificial neural network (ANN). The anti-cancer activities GI50/0M of flavones and isoflavones in test group and two new flavonoids luteolin and daidzin from Perilla ocymoides $\mathrm{L}$ and Glucine max L [1] resulting from in sillico models are compared with those from experimental data..

\section{Materials And Methods}

a. Materials: To ensure an accurate capability of QSAR model, the dataset used for building and validating QSAR models consists of 32 compounds with anti-cancer activities $\mathrm{GI}_{50} / \mu \mathrm{M}$

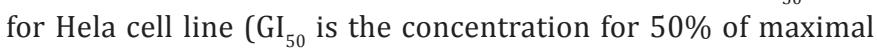
inhibition of cell proliferation) were reported by Wang et al. in the literature [2], as pointed out in (Figure 1). The value $\log \mathrm{GI}_{50}$ is the subsequent dependent variable that defines the biological parameter for QSAR model.<smiles>O=c1cc(-c2ccccc2)oc2ccccc12</smiles>

(a)<smiles>O=c1c(-c2ccccc2)coc2ccccc12</smiles>

(b)

Figure 1: Molecular skeleton: a) flavone and b) isoflavone.

$\mathrm{pGI}_{50}=-\log \mathrm{GI}_{50}$

Quantitative Structure-Activity Relationship

(QSAR) studies have often been used to find correlations between biological activities and 2D and 3D molecular descriptors for compounds. We used the flavones and isoflavones reported by Wang et al. to calculate 2D and 3D molecular descriptors. The molecular descriptors are calculated with QSARIS program [16]. The multiple linear regression (QSARMLR) and principal component regression (QSARPCR) models are constructed with XLSTAT 2014 [17]. Because of the artificial neural networks are an artificial intelligent systems, they use a large number of interrelated data-processing neurons to emulate the function of brain. So the artificial neural network (QSARPCA-ANN) can be constructed with program Visual Gene Developer 1.7 [18].

b. Constructing QSAR models: Linear regression is without doubt the most frequently used statistical method. The multiple regression (several explanatory variables) and simple linear regression are identical linear regression methods in the overall concept as well as calculation techniques. The principle of linear regression is to model a quantitative dependent variable $\mathrm{Y}$ though a linear combination of $\mathrm{k}$ quantitative explanatory variables, $\mathrm{x} 1, \mathrm{x} 2, \ldots, \mathrm{xk}$. In the case where there are $\mathrm{N}$ observations, the estimation of the predicted value of the dependent variable $Y$ is given by $[17,19]$ :

$$
\mathrm{Y}=\sum_{i=1}^{k} a_{\mathrm{i}} x_{i}+b(2)
$$

Where $\mathrm{Y}$ is the experimental activity $\mathrm{pGI}_{50^{\prime}}, \mathrm{exp}, \mathrm{x}_{\mathrm{i}}$ is $\mathrm{k}^{\text {th }}$ molecular descriptor.

Values $\mathrm{R}_{\text {train }}^{2}$ and $\mathrm{R}_{\text {pred }}^{2}$ are calculated by

$$
R^{2}=1-\frac{\sum_{i=1}^{N}\left(\mathrm{Y}_{i}-\hat{\mathrm{Y}}_{i}\right)^{2}}{\sum_{i=1}^{N}\left(\mathrm{Y}_{i}-\overline{\mathrm{Y}}\right)^{2}}
$$

Here $Y i, \hat{Y}_{i}$ are experimental $\mathrm{pGI}_{50}$ exp and predicted $\mathrm{pGI}_{50}$, pred value; $\bar{Y}$ is mean of experimental values.

The predicted results derived from the QSAR models are validated and compared with experimental data base on the relative errors (ARE, \%) as $[3,7]$ :

$$
A R E, \%=100\left|\left(\mathrm{pGI}_{50, \text { exp }}-\mathrm{pGI}_{50, \text { pred }}\right) / \mathrm{pGI}_{50, \exp }\right|
$$

The average value of absolute relative errors ARE, \% [6] is calculated and used for assessing the global uncertainty of QSAR model

$$
\text { MARE, } \%=\frac{100}{N}\left|\frac{\left(\mathrm{pGI}_{50, \text { exp }}-\mathrm{pGI}_{50, \text { pred }}\right)}{\mathrm{pGI}_{50, \exp }}\right|
$$

With $N$ is number of activity values.

Principal component regression (PCR) model [17,20] is a regression technique using principal component analysis (PCA) when evaluating regression coefficients. PCR presents a technique for finding structure in datasets. Its object is to group correlated variables, replacing the earlier descriptors by new set called principal components (PCs). These PC's are uncorrelated and are developed as a simple linear aggregation of earlier variables. It moves the data into a new set of axes such that first few axes indicate most of the variations within the data. First PC (PC1) is expressed in the direction of maximum variance of the whole dataset. Second PC (PC2) is the direction that defines the maximum variance in orthogonal subspace to PC1. Consequent components are taken orthogonal to the particular formerly 


\section{Organic and Medicinal Chemistry International Journal}

chosen and defines best of remaining variance, by locating the data on new set of axes, it can points major fundamental structures certainly. Value of each point, when moved to a given axis, is called the PC value. PCA chooses a new set of axes for the data. These are chosen in decreasing order of variance within the data. The aim of principal component regression PCR is the computation of values of a response variable on the basis of chosen PCs of independent variables $[16,17,20]$.

\section{Results And Discussion}

a. Calculation of molecular descriptors: The program HyperChem 8.05 [21] was used for designing the flavonoid molecules. The molecular structures were optimized by means of $\mathrm{MM}+$ molecular mechanics. The molecular descriptors of molecules were calculated by computational techniques of QSARIS [16] using the optimized geometries. The molecular descriptors were used to construct the multiple linear regression
$\left(\mathrm{QSAR}^{\mathrm{MLR}}\right)$, principal component regression $\left(\mathrm{QSAR}^{\mathrm{PCR}}\right)$ and artificial neural network $\left(\mathrm{QSAR}_{\mathrm{PCA}-\mathrm{ANN}}\right)$ model $[4,5]$.

b. Development of $\mathbf{Q S A R}_{\mathrm{MLR}}$ model: Before conducting the $\mathrm{QSAR}_{\mathrm{MLR}}$ model, the activity values $\mathrm{GI}_{50}(\mu \mathrm{M})$ are transformed into the values $\mathrm{pGI}_{50}$ to adapt the statistical properties. The values $\mathrm{pGI}_{50}(\mu \mathrm{M})$ are most appropriate value for modelling the relationships between molecular descriptors and activities. The $\mathrm{QSAR}_{\mathrm{MLR}}$ models were established by using the relationship of the geometric predictors and biological activities $\mathrm{pGI}_{50}[16]$. The QSAR models in this work obtained by two different approaches: (i) cases are selected randomly for training set, and (ii) remaining cases for validation of predictability (test set). There are several methods for selecting the training set. The simplest way is the random selection. In this work, the original data is divided into training and validation set. The accurate predictability of QSAR model is evaluated by comparing the predicted and observed activities of the substances in test set without training set.

Table 1: Molecular structure and activities $\mathrm{GI}_{50}(\mu \mathrm{M})$ of flavones and isoflavones [2].

\begin{tabular}{|c|c|c|c|c|c|}
\hline Substance & Name & Substitutive site & Substitutes R & GI50 $(\mu \mathrm{M})$ & \\
\hline \multicolumn{6}{|c|}{ Training set for establishing QSAR models } \\
\hline Fla1 & $1 \mathrm{a}-1$ & flavone & $\mathrm{C}_{3}$ & $-\mathrm{OCH}_{2} \mathrm{CCH}_{3}=\mathrm{NOH}$ & 2.0 \\
\hline Fla2 & $1 \mathrm{~b}$ & flavone & $\mathrm{C}_{6}$ & $-\mathrm{OCH}_{2} \mathrm{CCH}_{3}=\mathrm{NOH}$ & 1.2 \\
\hline Fla5 & $4 a$ & flavone & $\mathrm{C}_{3}$ & $-\mathrm{OCH}_{2} \mathrm{CCH}_{3}=\mathrm{NOCH}_{3}$ & 2.0 \\
\hline Fla6 & $5 a$ & flavone & $\mathrm{C}_{3}$ & $-\mathrm{OCH}_{2} \mathrm{CCH}_{3}=\mathrm{NOCH}_{3}$ & 0.9 \\
\hline Fla7 & $6 a$ & flavone & $\mathrm{C}_{7}$ & $-\mathrm{OCH}_{2} \mathrm{CCH}_{3}=\mathrm{NOCH}_{3}$ & 2.2 \\
\hline Isofla8 & $7 a$ & isoflavone & $\mathrm{C}_{7}$ & $-\mathrm{OCH}_{2} \mathrm{CCH}_{3}=\mathrm{NOCH}_{3}$ & 8.5 \\
\hline Fla10 & $8 a$ & flavone & $\mathrm{C}_{3}$ & $-\mathrm{OCH}_{2} \mathrm{C}(4-\mathrm{F}-\mathrm{C} 6 \mathrm{H} 4)=\mathrm{NOH}$ & 2.1 \\
\hline Fla11 & $9 \mathrm{a}$ & flavone & $\mathrm{C}_{3}$ & $-\mathrm{OCH}_{2} \mathrm{C}(4-\mathrm{CH} 3 \mathrm{O}-\mathrm{C} 6 \mathrm{H} 4)=\mathrm{NOH}$ & 2.0 \\
\hline Fla12 & $3 b$ & flavone & $\mathrm{C}_{6}$ & $-\mathrm{OCH}_{2} \mathrm{C}\left(\mathrm{C}_{6} \mathrm{H}_{5}\right)=\mathrm{NOH}$ & 0.8 \\
\hline Fla13 & $10 \mathrm{a}$ & flavone & $\mathrm{C}_{6}$ & $-\mathrm{OCH}_{2} \mathrm{C}\left(4-\mathrm{F}-\mathrm{C}_{6} \mathrm{H}_{4}\right)=\mathrm{NOH}$ & 1.6 \\
\hline Fla14 & $11 \mathrm{a}$ & flavone & $\mathrm{C}_{3}$ & $-\mathrm{OCH}_{2} \mathrm{C}\left(4-\mathrm{CH}_{3} \mathrm{O}-\mathrm{C}_{6} \mathrm{H}_{4}\right)=\mathrm{NOH}$ & 1.0 \\
\hline Fla15 & $4 \mathrm{~b}$ & flavone & $\mathrm{C}_{7}$ & $-\mathrm{OCH}_{2} \mathrm{C}\left(\mathrm{C}_{6} \mathrm{H}_{5}\right)=\mathrm{NOH}$ & 2.0 \\
\hline Fla16 & $5 \mathrm{~b}$ & flavone & $\mathrm{C}_{7}$ & $-\mathrm{OCH}_{2} \mathrm{C}\left(4-\mathrm{F}-\mathrm{C}_{6} \mathrm{H}_{4}\right)=\mathrm{NOH}$ & 2.0 \\
\hline Fla17 & $12 \mathrm{a}$ & flavone & $\mathrm{C}_{7}$ & $-\mathrm{OCH}_{2} \mathrm{C}\left(4-\mathrm{CH}_{3} \mathrm{O}-\mathrm{C}_{6} \mathrm{H}_{4}\right)=\mathrm{NOH}$ & 2.0 \\
\hline Isofla18 & $13 a$ & isoflavone & $\mathrm{C}_{7}$ & $-\mathrm{OCH}_{2} \mathrm{C}\left(\mathrm{C}_{6} \mathrm{H}_{5}\right)=\mathrm{NOH}$ & 9.0 \\
\hline Isofla19 & $14 \mathrm{a}$ & isoflavone & $\mathrm{C}_{7}$ & $-\mathrm{OCH}_{2} \mathrm{C}\left(4-\mathrm{F}-\mathrm{C}_{6} \mathrm{H}_{4}\right)=\mathrm{NOH}$ & 7.8 \\
\hline Isofla20 & $15 \mathrm{a}$ & isoflavone & $\mathrm{C}_{7}$ & $-\mathrm{OCH}_{2} \mathrm{C}\left(4-\mathrm{CH}_{3} \mathrm{O}-\mathrm{C}_{6} \mathrm{H}_{4}\right)=\mathrm{NOH}$ & 7.6 \\
\hline Fla21 & $16 a$ & flavone & $\mathrm{C}_{3}$ & $-\mathrm{OCH}_{2} \mathrm{C}\left(\mathrm{C}_{6} \mathrm{H}_{5}\right)=\mathrm{NOCH}_{3}$ & 1.6 \\
\hline Fla23 & $18 \mathrm{a}$ & flavone & $\mathrm{C}_{3}$ & $-\mathrm{OCH}_{2} \mathrm{C}\left(4-\mathrm{CH}_{3} \mathrm{O}-\mathrm{C}_{6} \mathrm{H}_{4}\right)=\mathrm{NOCH}_{3}$ & 2.0 \\
\hline Fla24 & $19 \mathrm{a}$ & flavone & $\mathrm{C}_{6}$ & $-\mathrm{OCH}_{2} \mathrm{C}\left(\mathrm{C}_{6} \mathrm{H}_{5}\right)=\mathrm{NOCH}_{3}$ & 2.4 \\
\hline Fla25 & $20 \mathrm{a}$ & flavone & $\mathrm{C}_{6}$ & $-\mathrm{OCH}_{2} \mathrm{C}\left(4-\mathrm{F}-\mathrm{C}_{6} \mathrm{H}_{4}\right)=\mathrm{NOCH}_{3}$ & 2.3 \\
\hline Fla26 & $21 \mathrm{a}$ & flavone & $\mathrm{C}_{6}$ & $-\mathrm{OCH}_{2} \mathrm{C}\left(4-\mathrm{CH}_{3} \mathrm{O}-\mathrm{C}_{6} \mathrm{H}_{4}\right)=\mathrm{NOCH}_{3}$ & 2.0 \\
\hline Fla27 & $22 \mathrm{a}$ & flavone & $\mathrm{C}_{7}$ & $-\mathrm{OCH}_{2} \mathrm{C}\left(\mathrm{C}_{6} \mathrm{H}_{5}\right)=\mathrm{NOCH}_{3}$ & 6.6 \\
\hline Fla28 & $23 a$ & flavone & $\mathrm{C}_{7}$ & $-\mathrm{OCH}_{2} \mathrm{C}\left(4-\mathrm{F}-\mathrm{C}_{6} \mathrm{H}_{4}\right)=\mathrm{NOCH}_{3}$ & 2.7 \\
\hline Fla29 & $24 a$ & flavone & $\mathrm{C}_{7}$ & $-\mathrm{OCH}_{2} \mathrm{C}\left(4-\mathrm{CH}_{3} \mathrm{O}-\mathrm{C}_{6} \mathrm{H}_{4}\right)=\mathrm{NOCH}_{3}$ & 2.5 \\
\hline Isofla30 & $25 a$ & isoflavone & $\mathrm{C}_{7}$ & $-\mathrm{OCH}_{2} \mathrm{C}\left(\mathrm{C}_{6} \mathrm{H}_{5}\right)=\mathrm{NOCH}_{3}$ & 8.2 \\
\hline Isofla31 & $26 a$ & isoflavone & $\mathrm{C}_{7}$ & $-\mathrm{OCH}_{2} \mathrm{C}\left(4-\mathrm{F}-\mathrm{C}_{6} \mathrm{H}_{4}\right)=\mathrm{NOCH}_{3}$ & 6.4 \\
\hline \multicolumn{6}{|c|}{ Test set for validating QSAR models } \\
\hline Fla3 & $2 a-3$ & flavone & $\mathrm{C}_{7}$ & $-\mathrm{OCH}_{2} \mathrm{CCH}_{3}=\mathrm{NOH}$ & 2.0 \\
\hline
\end{tabular}




\section{Organic and Medicinal Chemistry International Journal}

\begin{tabular}{|c|c|c|c|c|c|}
\hline Isofla4 & $3 \mathrm{a}-4$ & isoflavone & $\mathrm{C}_{7}$ & $-\mathrm{OCH}_{2} \mathrm{CCH}_{3}=\mathrm{NOH}$ & 9.8 \\
\hline Fla9 & $2 \mathrm{~b}$ & flavone & $\mathrm{C}_{3}$ & $-\mathrm{OCH}_{2} \mathrm{C}\left(\mathrm{C}_{6} \mathrm{H}_{5}\right)=\mathrm{NOH}$ & 1.8 \\
\hline Fla22 & $17 \mathrm{a}$ & flavone & $\mathrm{C}_{3}$ & $-\mathrm{OCH}_{2} \mathrm{C}\left(4-\mathrm{F}-\mathrm{C}_{6} \mathrm{H}_{4}\right)=\mathrm{NOCH}_{3}$ & 2.0 \\
\hline Fla28 & $23 \mathrm{a}$ & flavone & $\mathrm{C}_{7}$ & $-\mathrm{OCH}_{2} \mathrm{C}\left(4-\mathrm{F}-\mathrm{C}_{6} \mathrm{H}_{4}\right)=\mathrm{NOCH}_{3}$ & 2.7 \\
\hline Isofla32 & $6 \mathrm{~b}$ & isoflavone & $\mathrm{C}_{7}$ & $\left.-\mathrm{OCH}_{2} \mathrm{C}_{4} 4-\mathrm{CH}_{3} \mathrm{O}-\mathrm{C}_{6} \mathrm{H}_{4}\right)=\mathrm{NOCH}_{3}$ & 7.3 \\
\hline
\end{tabular}

Table 2: The QSARMLR models ( $k$ from 2 to 10 ) with change of values R2train, R2pred and SE.

\begin{tabular}{|c|c|c|c|c|}
\hline $\mathbf{k}$ & The 2D, 3D molecular descriptors in models & $\mathbf{R}_{\text {train }}^{2}$ & $\mathbf{R}_{\text {pred }}^{2}$ & SE \\
\hline 2 & LogP, MaxNeg & 0.756 & 0.731 & 0.430 \\
\hline 3 & LogP, MaxNeg, ka2 & 0.774 & 0.732 & 0.417 \\
\hline 4 & LogP, MaxNeg, ka2, SdO & 0.805 & 0.772 & 0.390 \\
\hline 5 & LogP, MaxNeg, MaxQp, SdO, ka2 & 0.832 & 0.756 & 0.365 \\
\hline 6 & LogP, MaxQp, Ovality, SdO, SdssC, ka3 & 0.854 & 0.812 & 0.342 \\
\hline 7 & LogP, MaxNeg, MaxQp, ka2, SdO, ABSQ, ABSQon, & 0.836 & 0.721 & 0.365 \\
\hline 8 & LogP , MaxNeg, MaxQp, ka2, SdO , ka3, ABSQ ABSQon & 0.837 & 0.693 & 0.367 \\
\hline 9 & LogP, MaxNeg, MaxQp, ka2, SdO, ka3, ABSQ ,ABSQon, Dipole & 0.838 & 0.682 & 0.369 \\
\hline 10 & LogP, MaxNeg, MaxQp, ka2, SdO, ka3, ABSQ, ABSQon, Dipole, Ovality & 0.841 & 0.650 & 0.368 \\
\hline
\end{tabular}

In recent years theoretical and experimental researchers have focused an increasing attention on finding the most efficient tools for selecting molecular descriptors in QSAR studies $[3,4,10]$. The change of values $\mathrm{R}_{2}^{\text {train }}, \mathrm{R}_{\text {pred }}^{2}$ and $\mathrm{SE}$ (standard error) in the $\mathrm{QSAR}_{\mathrm{MLR}}$ models with the 2D and 3D predictors, respectively are pointed out in (Table 1). To have those $\mathrm{QSAR}_{\mathrm{MLR}}$ models, the 2D and 3D molecular descriptors were selected by using forward and backward algorithm. The selection process for 2D and 3D descriptors based on the change of the statistical values $\mathrm{R}_{\text {train, }}^{2}$ $\mathrm{SE}$ and $\mathrm{R}^{2}$ pred. The values $\mathrm{R} 2$ pred of the $\mathrm{QSAR}_{\mathrm{MLR}}$ models were calculated by using the cross-validated technique with leaveone-out (LOO) method. The 9 fitness models are shown in (Table 2).

Table 3: Statistical values and valuable contribution percentages MPmxk, \% and GMPmxk, \% for 2D and 3D molecular descriptors in the models $\mathrm{QSAR}_{\text {MLR }}$ (with $\mathrm{k}$ of 5,6 and 7 ).

\begin{tabular}{|c|c|c|c|c|c|c|c|}
\hline \multirow{2}{*}{$\begin{array}{c}\text { Variable } \\
\mathbf{x}_{\mathrm{k}}\end{array}$} & \multicolumn{3}{|c|}{ QSAR $_{\text {MLR }}$} & \multicolumn{3}{|c|}{$\mathrm{MP}_{\mathrm{m}} \mathbf{x}_{\mathrm{k}}, \%$} & \multirow{2}{*}{$\frac{\mathrm{GMP}_{\mathrm{m}} \mathbf{X}_{\mathrm{k}^{\prime}}}{\%}$} \\
\hline & $k=5$ & $k=6$ & $k=7$ & $k=5$ & $k=6$ & $k=7$ & \\
\hline $\mathrm{R}_{\text {train }}^{2}$ & 0.832 & 0.854 & 0.836 & & & & \\
\hline $\mathrm{R}^{2}{ }_{\text {adj }}$ & 0.820 & 0.841 & 0.820 & & & & \\
\hline SE & 0.365 & 0.342 & 0.365 & & & & \\
\hline $\mathrm{R}_{\text {pred }}^{2}$ & 0.756 & 0.812 & 0.721 & & & & \\
\hline Constants & 3.883 & 8.509 & 4.790 & & & & \\
\hline ABSQ & -0.222 & - & -0.257 & 27.945 & 18.636 & 19.005 & 21.862 \\
\hline ABSQon & - & - & 0.0143 & - & - & 0.433 & 0.144 \\
\hline MaxQp & 3.416 & 2.8540 & 3.588 & 24.043 & 25.862 & 25.908 & 25.271 \\
\hline MaxNeg & - & - & 6.122 & - & 24.203 & 23.890 & 16.031 \\
\hline SdO & 0.0125 & 0.0247 & 0.0126 & 6.192 & 3.792 & 3.665 & 4.550 \\
\hline ka2 & 0.133 & - & 0.143 & 27.484 & 17.617 & 17.426 & 20.842 \\
\hline $\log P$ & 0.156 & 0.2192 & 0.163 & 15.651 & 9.829 & 9.672 & 11.717 \\
\hline Ovality & - & -3.6969 & - & 5.292 & 4.393 & 2.315 & 4.000 \\
\hline SdssC & - & 0.2969 & - & 4.382 & 5.613 & 7.236 & 5.744 \\
\hline ka3 & - & 0.3635 & - & 5.351 & 9.324 & 3.473 & 6.049 \\
\hline
\end{tabular}




\section{Organic and Medicinal Chemistry International Journal}

The QSAR ${ }_{\mathrm{MLR}}$ models (with $\mathrm{k}$ of 2 to 10 ) that were arranged in an orderly change of $\mathrm{R}_{\text {train, }}$, $\mathrm{SE}$ and $\mathrm{R}^{2}$ pred , as given in (Table 2). The values of $\mathrm{R}_{\text {train }}^{2}$ and $\mathrm{R}_{\text {pred }}^{2}$ from $\mathrm{QSAR}_{\mathrm{MLR}}$ models (with $\mathrm{k}$ from 5 to 7) are higher than others. In particular, the $\mathrm{QSAR}_{\mathrm{MLR}}$ model (with $\mathrm{k}=6$ ) has given the highest values $\mathrm{R}_{\text {train }}^{2}$ of 0.854 and $\mathrm{R} 2$ pred of 0.812 . So, three best models (with $\mathrm{k}$ of 5, 6 and 7) are chosen to determine the significant contribution of 2D, 3D descriptors. The valuable contribution percentages $M P_{m} x_{k} \%$ and $\mathrm{GMP}_{\mathrm{m}} \mathrm{x}_{\mathrm{k}^{\prime}} \%$ [3], with the statistical parameters of three models (with $\mathrm{k}$ of 5, 6 and 7), respectively, are given in (Table 3).

The contribution percentages $\mathrm{MP}_{\mathrm{m}} \mathrm{x}_{\mathrm{k}^{\prime}} \%, \mathrm{GMP}_{\mathrm{m}} \mathrm{x}_{\mathrm{k}^{\prime}} \%[3,7,11]$ of the models (with $\mathrm{k}$ of 5, 6 and 7), respectively are calculated by formula

$$
M P_{m} x_{k}, \%=\frac{1}{N} \sum_{j=1}^{N}\left(100 \cdot\left|b_{m, i} x_{m, i}\right| / \mathrm{C}_{\text {total }}\right) \text { with } \mathrm{C}_{\text {total }}=\sum_{j=1}^{k}\left|b_{m, k} x_{m, k}\right|
$$

Where $N$ the total number of cases, $m$ number of variables. The global average contribution percentage $\mathrm{GMP}_{\mathrm{m}} \mathrm{x}_{\mathrm{k}^{\prime}} \%$ of each independent variable for 3 models is determined by the formula

$$
G M P_{m} x_{k}, \%=\frac{1}{n} \sum_{n=1}^{3} M P_{m} x_{k}
$$

With $n$ number of models

The contribution percentages $\mathrm{GMP}_{\mathrm{m}} \mathrm{x}_{\mathrm{k}^{\prime}} \%$ in Table 3 depicted the important level of 2D and 3D molecular descriptors for flavonoid compounds. For the $\mathrm{QSAR}_{\mathrm{MLR}}$ models in Table 3 the important significance of 2D and 3D molecular descriptors is arranged by using values $G M P_{m} x_{k^{\prime}} \%$ : MaxQp > ABSQ > ka2 > MaxNeg $>\log \mathrm{P}>\mathrm{ka} 3>\mathrm{SdssC}>\mathrm{SdO}>$ Ovality $>$ ABSQon. The molecular descriptors MaxQp, ABSQ, ka2, MaxNeg and LogP can be considered such as the most important contribution for each molecule. Besides these molecular descriptors exhibit by important nature of carbonyl group $\mathrm{C}_{4}=\mathrm{O}_{11}$ and atom $\mathrm{O}_{1}$. These atoms wear the free electron pair conjugating with $\pi$ electronic bond $\mathrm{C}_{2}=\mathrm{C}_{3}$, and $\mathrm{C}_{4}=\mathrm{O}_{11}$ to form a conjugate system. The carbonyl group $\mathrm{C}_{4}=\mathrm{O}_{11}$ exhibited fully reactive nature of carbonyl substance [2]. So, these descriptors can be demonstrated quantitatively total charges ABSQ, MaxQp and MaxNeg on molecule based on the values GMPmxk, \% and these are also consistent with the verdicts from experimental evaluation [16,23]. Furthermore, the atomic positions $C_{6}$ and $\mathrm{C}_{3}{ }^{\prime}$ on molecule are the vacant positions and can be explored for attaching the new function groups $[9,23,24]$. The various atoms seem to be the important impacts for biological activities $\mathrm{GI}_{50}$. So these sites are chosen for attaching the new substitutes to construct new flavonoids. Similarly the atom $\mathrm{C}_{2}{ }^{\prime}$ is also empty position and also can be utilized to attach the new function group. Those sites hope to constitute the new compounds with higher activity than sample compound. Also this way, the new flavonoids isolated from leaves of Perilla ocymoides $L$ and Glucine $\max L$ are also used such as lead compounds to design new drugs. This is also showed in below discussion.

c. Development of $\mathbf{Q S A R}_{\mathbf{P C R}}$ model: The molecular descriptors were applied to under goes principal component regression PCR technique to create $\mathrm{QSAR}_{\mathrm{PCR}}$ model with simulated anealining variable selection mode by using PCR model [17]. The best $\mathrm{QSAR}_{\mathrm{MLR}}$ model (with $k=6$ ) is selected to generate the QSARPCR model $[16,17]$. The 6 independent variables MaxQp, SdO, ka3, LogP, Ovality and SdssC were carried out to analyse the principle components. The principle component regression $\mathrm{QSAR}_{\mathrm{PCR}}$ model is generated with 6 principle components which are corresponding to the original descriptors of $\mathrm{QSAR}_{\mathrm{MLR}}$ model (with $\mathrm{k}=6$ ), as exhibited in equation (8):

$$
\mathrm{pGI}_{50}=5.48356+0.38027 \times \mathrm{PC}_{1}-0.11868 \times \mathrm{PC}_{2}+0.34789 \times \mathrm{PC}_{3}
$$
$+0.06995 \times \mathrm{PC}_{4}+0.21850 \times \mathrm{PC}_{5}+0.35057 \times \mathrm{PC}_{6}$

With $n=26 ; \mathrm{R}_{\text {train }}^{2}=0.937 ; \mathrm{R}^{2}{ }_{\text {Adj }}=0.9106, \mathrm{R}_{\text {Pred }}^{2}=0.889, \mathrm{SE}=$ $0.342, \mathrm{MSE}=0.1236 ; \mathrm{F}=63.172$

The number of principle components is extracted by the principle component analysis technique and the the correlation between $\mathrm{pGI}_{50}$ and $\mathrm{pGI}_{50}$, pred values is pointed out in (Figure 2).

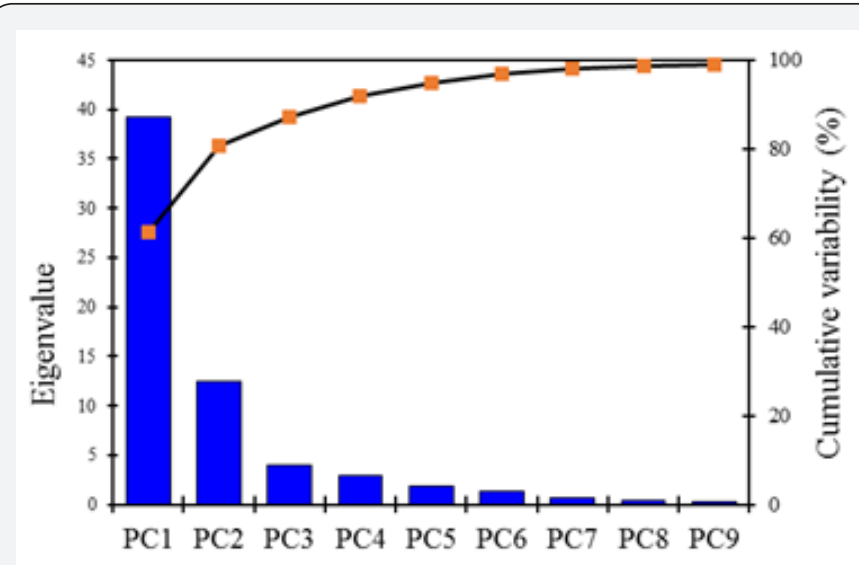

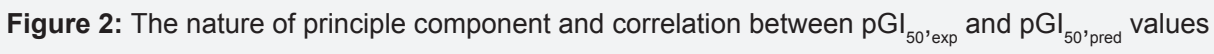




\section{Organic and Medicinal Chemistry International Journal}

d. Building $\mathbf{Q S A}_{\mathrm{RPCA}-\mathrm{ANN}}$ model: The $\mathrm{QSAR}_{\mathrm{PCA}-\mathrm{ANN}}$ model is built by the neuro-fuzzy technique with the genetic algorithms using program Visual Gene Developer v1.7 [18]. The artificial neural network has an architecture style I(6)-HL(9)-O(1); it consists of input layer I(6) with 6 neurons such as 6 principle components in equation (8) $\mathrm{PC}_{1}, \mathrm{PC}_{2}, \mathrm{PC}_{3}, \mathrm{PC}_{4}, \mathrm{PC}_{5}$ and PC6; the input neurons are corresponding to LogP, MaxQp, Ovality, SdO, SdssC and ka3; the neuron of output layer O(1) is the biological activity $\mathrm{pGI}_{50}$; the hidden layer HL(9) consists of nine neurons. This neural network I(6)-HL(9)-O(1) used the back propagation algorithm to train the network.

The back propagation algorithm looks for the minimum of the error function in weight space using the method of gradient descent. The sigmoid function is used to transfer on each node of neural network; the training parameters of neural network are the training rate of 0.7 and learing rate of 0.7 ; the goal monitoring error MSE $=0.000816$ with 10,000 iteration. After training the QSAR $_{\mathrm{PCA}}$-ANN with architecture I(6)-HL(9)-O(1) pointed out the values $\mathrm{R}_{\text {train }}^{2}$ of 0.993 and $\mathrm{R}^{2}$ pred of 0.971 . But in the case the $\mathrm{QSAR}_{\mathrm{PCR}}$ model gave values $\mathrm{R}_{\text {train }}^{2}=0.937$ and $\mathrm{R}_{\text {pred }}^{2}=0.889$; and the $\mathrm{QSAR}_{\mathrm{MLR}}$ model (with $\mathrm{k}=6$ ) gave values $\mathrm{R}_{\text {train }}^{2}$ of 0.854 and $\mathrm{R}_{\text {pred }}^{2}$ of 0.812 .

\section{e.Isolation of luteolin and daidzin from plant}

i. Chemicals and equipment: In this work, we used the chemicals and the equipments for isolating and purifying two flavonoids luteolin and daidzin before determining the substance structures by 1H-NMR and 13C-NMR spectrum [25].
The following materials are used to isolate the flavonoids in

ii. Silica gel with the particle size in range 0.04 to $0.06 \mathrm{~mm}$ was used for ordinary and Rp18 phase chromatography.

iii. Thin-layer chromatography was implemented by the thin plate DC-Alufolien F254 (Merck) for the ordinary phase and Rp18 F254s (Merck) for the reverse-phase chromatography.

iv. Solvents used for the isolation processes: hexane, petroleum ether, chloroform, methanol, ethyl acetate, ethanol, acetone, distilled water.

v. UV handheld lamps, 254 and $365 \mathrm{~nm}$ UVITEC effect.

vi. Vacuum Evaporators Buchi - 111 and Water Bath cooker JULABO 461.

vii. Infrared heating equipment SCHOTT.

viii. Chromatography column with diameter range 2 to 5.5 $\mathrm{cm}$.

ix. Analytical Balances AND HR 200.

f. Isolation process of luteolin and daidzin: To isolate and purify the luteolin and daidzin compound from the leaves of Perilla ocymoides L and Glucine max $L$ we used the techniques of thin-layer and column chromatography [25], as exhibited in (Figures 3-4). After isolating the compounds their structures were identified by the different spectrum as

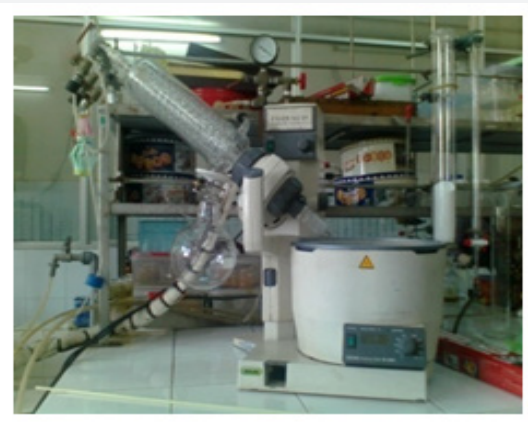

a) Vacuum Evaporators

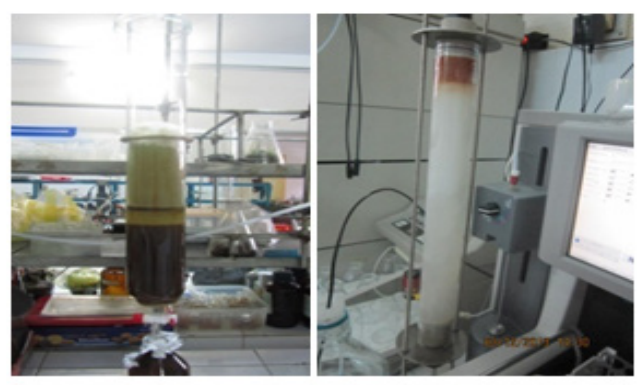

b) Column chromatography at atmospheric and high pressure

Figure 3: Separate equipment for two flavonoids luteolin and daidzin.

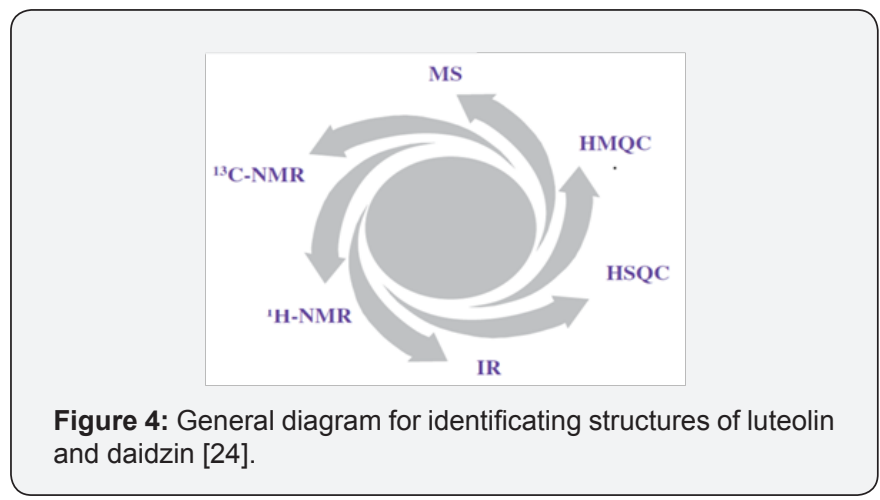

i. Melting temperature carried out on Electrothermal IA 9000 series, using unadjusted capillary.

ii. Column chromatography with silica gel for ordinaryphase, reverse-phase chromatography Rp 18 and sephadex techniques combined with thin-layer chromatography.

iii. Substances were detected by ultraviolet light at wavelengths $254 \mathrm{~nm}$ and $365 \mathrm{~nm}$ or reagent used is liquid $\mathrm{H}_{2} \mathrm{SO}_{4} / \mathrm{EtOH}$ or $\mathrm{FeCl}_{3} / \mathrm{EtOH}$.

iv. Nuclear magnetic resonance spectrum (NMR) ${ }^{1} \mathrm{H}-\mathrm{NMR}$ 


\section{Organic and Medicinal Chemistry International Journal}

(500 MHz) and ${ }^{13} \mathrm{C}$-NMR (125 MHz) implemented on Bruker AM500 FT-NMR Spectrometer.

g. Prediction of biological activity for new substances: The predictability of the constructed models $\mathrm{QSAR}_{\mathrm{MLR}}, \mathrm{QSAR}_{\mathrm{PCR}}$ and $\mathrm{QSAR}_{\mathrm{PCA}-\mathrm{ANN}}$ was evaluated carefully by using the leave-oneout (LOO) technique to determine $\mathrm{R}^{2}{ }_{\text {pred }}$; the flavonoids in Table 1 were divided randomly into the training group of 26 compounds and the test group of 6 compounds. The anticancer activities $\mathrm{pGI}_{50}$ of 6 flavonoids in the test group in Table 1 with 2 new flavonoids luteolin and daidzin isolated from the leaves of Perilla ocymoides L and Glucine max L [1] are predicted from those QSAR models. The predicted activities of 6 flavonoids in test group and new substances luteolin and daidzin resulting from QSAR models were compared to experimental data, as presented in (Table 4). For new substances luteolin and daidzin we carried out to test the in vitro activity on Hela cell line in laboratory of molecular biology of the genetic department at Ho Chi Minh University of science (Figure 5).

Table 4: Biological activities $\mathrm{pGI}_{50}$ of 6 flavonoids in test group and two new substances luteolin and daidzin resulting from models $\mathrm{QSAR}_{\mathrm{MLR}}$, $\mathrm{QSAR}_{\mathrm{PCR}}$ and QSAR $\mathrm{PCA}-\mathrm{ANN}$.

\begin{tabular}{|c|c|c|c|c|c|c|c|c|}
\hline \multirow{2}{*}{ Substance } & \multirow{2}{*}{ Ref. } & \multirow{2}{*}{ pGI $\mathbf{I 0}_{\text {'exp }}$} & \multicolumn{3}{|c|}{ pGI $_{50^{\prime} \text { pred }}$} & \multicolumn{3}{|c|}{ ARE,\% } \\
\hline & & & QSAR $_{\text {MLR }}$ & $\mathbf{Q S A R}_{\mathrm{PCR}}$ & $\mathbf{Q S A R}_{\text {PCA-ANN }}$ & QSAR $_{\text {MLR }}$ & $\mathbf{Q S A R}_{\mathrm{PCR}}$ & QSAR $_{\text {PCA-ANN }}$ \\
\hline Fla3 & {$[8,12,13]$} & 5.699 & 5.632 & 5.560 & 5.673 & 1.179 & 2.439 & 0.454 \\
\hline Isofla4 & {$[8,12,13]$} & 5.009 & 5.077 & 5.112 & 5.123 & 1.352 & 2.060 & 2.278 \\
\hline Fla9 & {$[8,12,13]$} & 5.745 & 5.690 & 5.740 & 5.687 & 0.954 & 0.082 & 1.006 \\
\hline Fla22 & {$[8,12,13]$} & 5.699 & 5.785 & 5.614 & 5.765 & 1.511 & 1.491 & 1.162 \\
\hline Fla28 & {$[8,12,13]$} & 5.569 & 5.653 & 5.559 & 5.668 & 1.510 & 0.172 & 1.783 \\
\hline Isofla32 & {$[8,12,13]$} & 5.137 & 5.088 & 5.115 & 5.064 & 0.948 & 0.422 & 1.413 \\
\hline luteolin & this work & 5.032 & 4.415 & 4.979 & 5.106 & 12.262 & 1.053 & 1.476 \\
\hline daidzin & this work & 5.103 & 4.592 & 4.637 & 4.982 & 10.014 & 9.124 & 2.382 \\
\hline & & & & & MARE,\% & 3.716 & 2.106 & 1.494 \\
\hline
\end{tabular}

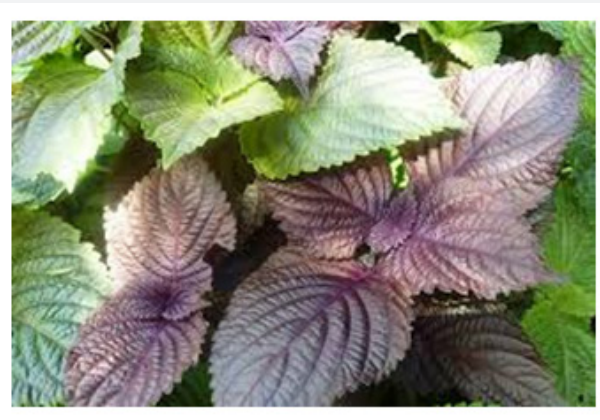

a) leaf of Perilla ocymoides $L$ [1]<smiles>O=c1cc(-c2ccc(O)c(O)c2)oc2cc(O)cc(O)c12</smiles>

Luteolin with $\mathrm{GI}_{50, \exp }(\mu \mathrm{M})=5.032 \pm 0.321$

Figure 5: The molecular structures of: a) luteolin and b) daidzin.

The luteolin structure was identified by using the different spectra such: ${ }^{1} \mathrm{H}-\mathrm{NMR}$ (DMSO-d $\left.{ }_{6}, 500 \mathrm{MHz}, \delta \mathrm{ppm}\right)$ with $\mathrm{HSQC}$, HMBC: $\delta 6.65\left(1 \mathrm{H} ; \mathrm{s}, \mathrm{H}_{3}\right) ; 6.19\left(1 \mathrm{H}\right.$; d; J = 2Hz, $\left.\mathrm{H}_{6}\right) ; 6.45(1 \mathrm{H}$; d; J = 2Hz, $\left.\mathrm{H}_{8}\right)$; $7.4\left(1 \mathrm{H} ; \mathrm{s} \mathrm{H}_{2}{ }^{\prime}\right) ; 6.89\left(1 \mathrm{H} ; \mathrm{d} ; \mathrm{J}=8 \mathrm{~Hz}, \mathrm{H}_{5}\right) ; 7.41$ $\left(1 \mathrm{H} ; \mathrm{d} ; \mathrm{J}=8 \mathrm{~Hz}, \mathrm{H}_{6}\right) ; 12.95(1 \mathrm{H}, \mathrm{s} ; \mathrm{C} 5-\mathrm{OH}) ; 9.4\left(1 \mathrm{H}, \mathrm{s}, \mathrm{C}_{4^{\prime}}-\mathrm{OH}\right)$; 9.9(1H, s, C3'-OH); 10.84 (1H, s, C7-OH). The 13C-NMR spectrum was employed to have more information such as combining

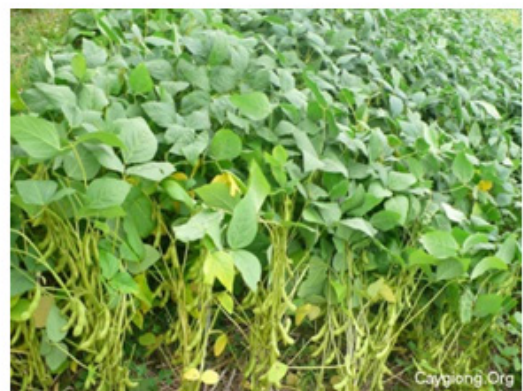

b) leaf of Glucine $\max L$ [1]<smiles>C[C@@H]1[C@@H](CO)O[C@@H](Oc2ccc3c(=O)c(-c4ccc(O)cc4)coc3c2)[C@H](C)[C@H]1O</smiles>

daidzin with $\mathrm{GI}_{50, \exp }(\mu \mathrm{M})=7.88 \pm 0.195$ 


\section{Organic and Medicinal Chemistry International Journal}

$\mathrm{C}_{9}-\mathrm{C}_{10} ; \mathrm{H}_{2},-\mathrm{C}_{2}-\mathrm{C}_{3},-\mathrm{C}_{4^{\prime}}-\mathrm{C}_{6} ; \mathrm{H}_{3^{\prime}}-\mathrm{C}_{1^{1}}-\mathrm{C}_{2^{\prime}}, \mathrm{C}_{4^{\prime}}-\mathrm{C}_{5^{\prime}} ; \mathrm{H}_{5^{\prime}}, \mathrm{C}_{1^{1}}, \mathrm{C}_{3^{\prime}}-\mathrm{C}_{4^{\prime}}, \mathrm{C}_{6}$; $\mathrm{H}_{6},-\mathrm{C}_{2}-\mathrm{C}_{1},-\mathrm{C}_{2},-\mathrm{C}_{4},-{ }_{C 5}$,

For the substance daidzin the molecular structure was also identified by the spectrum ${ }^{1} \mathrm{H}-\mathrm{NMR}: \delta \quad 8,06(1 \mathrm{H}, \mathrm{d}, \mathrm{J}=8,0 \mathrm{~Hz}$, $\left.\mathrm{H}_{5}\right) ; \delta 7,15\left(1 \mathrm{H}, \mathrm{D}, \mathrm{J}=1,5 \mathrm{~Hz}, \mathrm{H}_{6}\right) ; \delta 7,23\left(1 \mathrm{H}, \mathrm{d}, \mathrm{J}=2,0 \mathrm{~Hz}, \mathrm{H}_{8}\right)$; $\delta$ 6,84 ppm (2H, d, J = 6,5 Hz, H3', $\left.\mathrm{H}_{5^{\prime}}\right) ; \delta \quad 7,42(2 \mathrm{H}, \mathrm{d}, \mathrm{J}=8,0$ $\mathrm{Hz}, \mathrm{H}_{6}, \mathrm{H}_{2}$ ); Also, we used specrum 13C-NMR (DMSO-d $\mathrm{d}_{6}, 125 \mathrm{~Hz}$ ) with spectra DEPT, HSQC, HMBC: $\delta 153,2\left(\mathrm{C}_{2}\right), \delta 122,3\left(\mathrm{C}_{3}\right), \delta$ $174,7\left(\mathrm{C}_{4}\right), \delta 126,9\left(\mathrm{C}_{5}\right), \delta 115,6\left(\mathrm{C}_{6}\right), \delta 161,3\left(\mathrm{C}_{7}\right), \delta 103,4\left(\mathrm{C}_{8}\right), \delta$ $157,0\left(\mathrm{C}_{9}\right), \delta 118,5\left(\mathrm{C}_{10}\right), \delta 123,7\left(\mathrm{C}_{1}\right), \delta 130,0\left(\mathrm{C}_{2}\right), \delta 115,0\left(\mathrm{C}_{3^{3}}\right)$, $\delta 157,2\left(\mathrm{C}_{4^{\prime}}\right), \delta 115,0\left(\mathrm{C}_{5^{\prime}}\right), \delta 130,0\left(\mathrm{C}_{6^{\prime}}\right), \delta 100,0\left(\mathrm{C}_{1^{\prime \prime}}\right), \delta 73,1\left(\mathrm{C}_{2^{\prime \prime}}\right)$, $\delta 76,5\left(\mathrm{C}_{3^{\prime \prime}}\right), \delta 69,6\left(\mathrm{C}_{4^{\prime \prime}}\right), \delta 77,2\left(\mathrm{C}_{5^{\prime \prime}}\right), \delta 60,6\left(\mathrm{C}_{6^{\prime \prime}}\right)$. The molecular structures of new substances luteolin and daidzin are shown in (Figure 5). The predicted activities from QSAR models were compared with experimental data and with each other upon the average value of absolute relative error MARE, \%. The values MARE, \% showed that the predictability of the model QSARMLR is lower than models QSARPCR and QSARPCA-ANN, as given in (Table 4). After using the QSAR models to predict the anticancer activities $\mathrm{pGI}_{50}$ of six flavonoids in test group and two new flavonoids luteolin and daidzin, the errors of QSAR models can be accepted in uncertainty range of experimental measurements. Consequently, the models $\mathrm{QSAR}_{\mathrm{MLR}^{\prime}} \mathrm{QSAR}_{\mathrm{PCR}}$ and $\mathrm{QSAR}_{\mathrm{PCA} A \mathrm{ANN}}$ exhibited in good adaptability for predicting the activities of new substances. In this work, we selected the new substance luteolin isolating from Perilla ocymoides L to design new substances. The new functional group are substituted at the vacant positions $\mathrm{C}_{6}$, $\mathrm{C}_{2}$, and $\mathrm{C}_{3^{\prime}}$.

Table 5: The anticancer activities $\mathrm{pGI}_{50}$ of 5 new flavonoids resulting from QSARPCA-ANN model.

\begin{tabular}{|c|c|c|c|c|c|}
\hline New substance & $\mathrm{C}_{6}$ & $\mathrm{C}_{2^{\prime}}$ & $\mathrm{C}_{3^{\prime}}$ & pGI50 & Method in this work \\
\hline luteolin & $\mathrm{H}$ & $\mathrm{H}$ & $\mathrm{H}$ & 5.032 & in vitro test on Hela \\
\hline flav-1 & $\mathrm{H}$ & $\mathrm{NO}_{2}$ & $\mathrm{H}$ & 5.781 & QSAR $_{\text {PCA-ANN }}$ \\
\hline flav-2 & $\mathrm{CH}_{3} \mathrm{CO}-$ & $\mathrm{H}$ & $\mathrm{NO}_{2}$ & 6.155 & $\mathrm{QSAR}_{\mathrm{PCA} \text {-ANN }}$ \\
\hline flav-3 & $\mathrm{CH}_{3} \mathrm{CO}-$ & $\mathrm{NO}_{2}$ & $\mathrm{H}$ & 6.158 & $\mathrm{QSAR}_{\mathrm{PCA}-\mathrm{ANN}}$ \\
\hline flav-4 & $\mathrm{NO}_{2}$ & $\mathrm{NO}_{2}$ & $\mathrm{H}$ & 6.488 & $\mathrm{QSAR}_{\mathrm{PCA}^{-} \mathrm{ANN}}$ \\
\hline flav-5 & $\mathrm{NO}_{2}$ & $\mathrm{H}$ & $\mathrm{NO}_{2}$ & 6.538 & $\mathrm{QSAR}_{\mathrm{PCA-ANN}}$ \\
\hline
\end{tabular}

The substance luteolin was used such as lead compound for designing 5 new various compounds. The positions $\mathrm{C}_{6}, \mathrm{C}_{2}$ ' and $\mathrm{C}_{3}$. were substituted the new functional groups; and the biological activities $\mathrm{pGI}_{50}$ of the new designed flavonoids were predicted by using $\mathrm{QSAR}_{\mathrm{PCA}-\mathrm{ANN}}$ model, as given in (Table 5). The predicted results $\mathrm{pGI}_{5}$ for 5 new designed substances are compared with experimental activity of luteolin, as depicted in (Figure 6). The activity $\mathrm{GI}_{50}(\mu \mathrm{M})$ of five new designed compounds from luteolin by substituting new functional groups into $\mathrm{C}_{6}, \mathrm{C}_{2}$, and $\mathrm{C}_{3^{3}}$, sites are stronger than lead compound luteolin. Herein the new designed compounds will promise to forward a designing plan for the new pharmaceutical products from natural products.

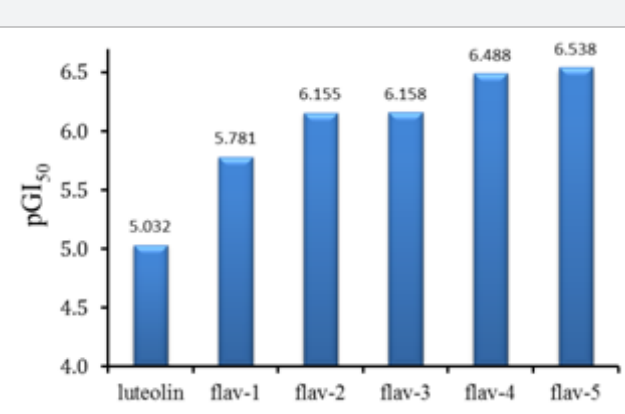

Figure 6: Comparison between values $\mathrm{pGI}_{50}$ of five new flavonoids with luteolin.

\section{Conclusion}

The use of computational methods constructed successfully the in sillico models with relationships between the 2D, 3D molecular descriptors and anti-cancer activities $\operatorname{GI} 50(\mu \mathrm{M})$ of flavonoids. The $\mathrm{QSAR}_{\mathrm{MLR}}$ model showed the important contribution descriptors MaxQp, SdO, ka3, LogP, Ovality and SdssC on flavonoids which effect an in vitro activity on Hela cell line. The in sillico model QSAR also found out helpfully the most important positions $\mathrm{C}_{6}$ and $\mathrm{C}_{3^{\prime}}$ to substitute the new functional groups to generate new flavonoids with higher activity than luteolin isolating from leaf of Perilla ocymoides L. The $\mathrm{QSAR}_{\mathrm{PCA}}$ ANN model with architecture I(6)-HL(9)-O(1) has the good applicability for flavonoids. The biological activities resulting from $\mathrm{QSAR}_{\mathrm{PCA}-\mathrm{ANN}}$ model turn out to be in good agreement with those from experimental data. The QSAR models described in the present paper for diverse flavonoids may be useful for in vitro toxicity assessment. This work established the different models QSAR that may prove to be useful for guiding the rational search of new therapeutic agents for cancer diseases.

\section{References}

1. Do Tat Loi (2006) Medicinal Plants and Drugs from Vietnam. Publisher of Medicine, Vietnam.

2. Manjinder Singh, Maninder Kaur, Om Silakari (2014) Flavones: an important scaffold for medicinal chemistry. European Journal of Medicinal Chemistry 84: 206-239.

3. Debarshi Kar Mahapatra, Sanjay Kumar Bharti, Vivek Asati (2015) Anti-cancer chalcones: Structural and molecular target perspectives. European Journal of Medicinal Chemistry 98: 69-114.

4. Lovro Ziberna, Stefano Fornasaro, Jovana Čvorović, Federica Tramer, Sabina Passamonti (2014) Polyphenols in Human Health and Disease 1: 489-511.

5. R Vidya Priyadarsini, R Senthil Murugan, S Maitreyi, K Ramalingam, D Karunagaran, et al. (2010) The flavonoid quercetin induces cell cycle 


\section{Organic and Medicinal Chemistry International Journal}

arrest and mitochondria-mediated apoptosis in human cervical cancer (HeLa) cells through p53 induction and NF-кB inhibition. European Journal of Pharmacology 649(1-3): 84-91.

6. Bożena Pawlikowska Pawlęga, Halina Dziubińska, Elżbieta Król, Kazimierz Trębacz, Anna Jarosz Wilkołazka, et al. (2014) Interaction of a quercetin derivative - lensoside $A \beta$ with liposomal membranes. Biochimica et Biophysica Acta (BBA) - Biomembranes, 1838(1): 254 265

7. Nathan M Gavin, Michael J Durako (2012) J. Experimental Marine Biology and Ecology 32(40): 416-417.

8. Iris S L Lee, Mary C Boyce, Michael C Breadmore (2012) Extraction and on-line concentration of flavonoids in Brassica oleracea by capillary electrophoresis using large volume sample stacking. J. Food Chemistry 133(1): 205-211.

9. Bui Thi Phuong Thuy Pham Van Tat (2012) Vietnam Journal of Chemistry 5(50): 550-556.

10. Bui Thi Phuong Thuy Pham Van Tat (2012) Vietnam Journal of Chemistry 50(5A): 203-208.

11. Pham Van Tat (2009) Vietnamese Journal of Chemistry and Application 14: 43-46.

12. Si Yan Liao, Jin Can Chen, Li Qian, Yong Shen, Kang Cheng Zheng, et al. (2005) J Bioorganic and Medicinal Chemistry 13: 6045-6053.

13. Si Yan Liao, Jin Can Chen, Li Qian, Yong Shen, Kang Cheng Zheng, et al. (2008) QSAR, action mechanism and molecular design of flavone and isoflavone derivatives with cytotoxicity against HeLa. J European Journal of Medicinal Chemistry 43(10): 2159-2170.

14. I Li Chen, Chen JY, Shieh PC, Chen JJ, Lee CH, et al. (2008) Synthesis and antiproliferative evaluation of amide-containing flavone and isoflavone derivatives. J Bioorganic and Medicinal Chemistry 16(16): 7639-7645.

15. TC Wang, IL Chen, PJ Lu, CH Wong, CH Liao, et al. (2005) Synthesis, antiproliferative, and antiplatelet activities of oxime-and methyloximecontaining flavone and isoflavone derivatives, Bioorganic \& Medicina Chemistry. Bioorg Med Chem 13(21): 6045-6053.
16. Pham Van Tat (2009) Development of Quantitative StructureActivity Relationships (QSARs) and Quantitative Structure-Property Relationships (QSPRs). Publisher of Natural Science and Technology, Hanoi.

17. XLSTAT version (2014) Copyright Addinsoft 1995-2014, USA.

18.Jung, SK, K McDonald (2011) Visual Gene Developer: a fully programmable bioinformatics software for synthetic gene optimization. BMC Bioinformatics 12(1): 340 .

19. Wold S (1995) PLS for multivariate linear modelling. In: van de Waterbeemd H, QSAR: Chemometric Methods in Molecular Design. Wiley-VCH, Weinheim, Germany 2: 195-218.

20. OriginLab tutorials, OriginLab Corporation, Northampton, MA 01060 USA (2015).

21. HyperChem Release (2008) Hypercube Inc USA.

22. Bastien P, Esposito Vinzi V, Tenenhaus M (2005) PLS Generalised Regression. Computational Statistics and Data Analysis 48: 17-46.

23. Pham Van Tat (2017) Development of New Anticancer Agents From Leaf of Plants In Viet Nam, LAP Lambert Academic Publishing, OmmiScriptum GmbH \& Co KG, Germany.

24. Bui Thi Phuong Thuy Pham Van Tat (2012) Vietnam Journal of Chemistry 50(5A): 203-208.

25. Bui Thi Phuong Thuy, Nguyen Thi Ai Nhung, Tran Duong, Phung Van Trung, Nguyen Minh Quang, et al. (2016) Prediction of anticancer activities of cynaroside and quercetin in leaf of plants Cynara scolymus $L$ and Artocarpus incisa $L$ using structure-activity relationship. Theoretical and Computational chemistry, Cogent Chemistry, Taylor \& Francis, Cogent Chemistry 2(1)

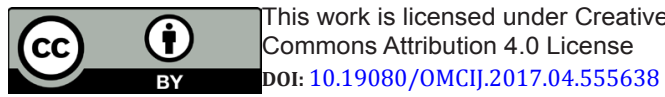

